\title{
Dos calas en el discurso del odio al andaluz, de la tradición libresca a
}

la prensa digital

\section{Two explorations of hate speech against the Andalusian variety, from the bookish tradition to the digital press}

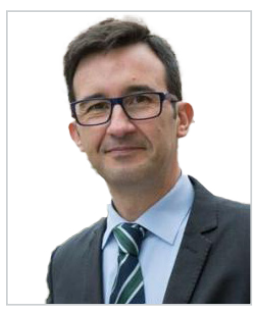

Francisco Manuel Carriscondo-Esquivel. Catedrático de Lengua Española en la Universidad de Málaga. Cuenta con numerosas publicaciones científicas en revistas como Boletín de la Real Academia Española, Bulletin Hispanique, Bulletin of Spanish Studies, Nueva Revista de Filología Hispánica, Revista de Filología Española, Revue Romane, Romance Philology, Romanistisches Jahrbuch, Zeitschrift für Romanische Philologie, etc. Associate Editor de Hispania. A Journal Devoted to the Teaching of Spanish and Portuguese. Ha desarrollado actividades docentes e investigadoras en instituciones académicas de reconocido prestigio en Alemania, Argentina, Austria, Chequia, España, Estados Unidos, Francia, Hungría, Italia, México, Perú, Portugal y Reino Unido. Es creador de los portales lenguayprensa.uma.es y dicciocho.org. Miembro Colaborador de la Academia Norteamericana de la Lengua Española y del Instituto de Estudios Medievales y Renacentistas de la Universidad de Salamanca. Universidad de Málaga, España esquivel@uma.es

ORCID: 0000-0002-1812-9609

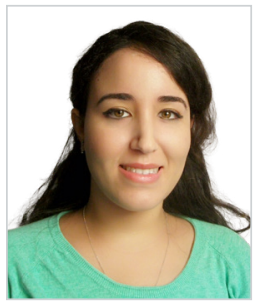

Amina El-Founti Zizaoui. Doctoranda en la Universidad de Málaga. Graduada en Filología Hispánica y Máster Oficial de Profesorado en Educación Secundaria Obligatoria por la misma universidad. Actualmente, es contratada predoctoral FPU (investigación y docencia) en el Área de Lengua Española de la Universidad de Málaga. Su principal línea de investigación es el estudio de las ideologías lingüísticas, sobre todo aplicadas a los medios de comunicación. Es miembro del grupo del grupo de investigación "Análisis de noticias sobre divulgación lingüística, las lenguas de España y sus variedades", que ejecuta el proyecto Lengua y Prensa.

Universidad de Málaga, España aminafz@uma.es

ORCID: 0000-0001-5127-0148

Recibido: 26/05/2020 Aceptado: 12/11/2020

Resumen:

Este trabajo persigue como objetivo trazar un recorrido de la percepción de la variedad del español hablada en Andalucía, desde sus comienzos en el siglo XVI hasta su presencia en soportes tecnológicos actuales, como los que evidencia la prensa digital. Para ello, seleccionaremos una serie de muestras representativas: referencias librescas de los siglos XVI al XIX, extractos audiovisuales procedentes de series de televisión y películas y, finalmente, textos periodísticos recogidos en la prensa digital española. El corpus
Received: 26/05/2020 - Accepted: 12/11/2020

\section{Abstract:}

The aim of this work is to trace a route on the perception of the variety of Spanish spoken in Andalusia, from its beginnings in the 16 th century to its presence in current technological supports, such as those evidenced by the digital press. For this purpose, we will select a series of representative samples: book references from the 16th to 19th centuries, audiovisual extracts from television series, films and, finally, journalistic texts collected in the Spanish digital press. The corpus arises as a result of our experience as researchers

Cómo citar este artículo:

Carriscondo-Esquivel, F. M.; El-Founti Zizaoui, A. (2020). Dos calas en el discurso del odio al andaluz, de la tradición libresca a la prensa digital. Doxa Comunicación, 31, pp. 251-264.

https://doi.org/10.31921/doxacom.n31a12 
surge como resultado de nuestra experiencia como investigadores de la representación literaria del andaluz y las actitudes lingüísticas reflejadas en los medios de comunicación, inventariadas estas últimas en un recurso disponible para toda la comunidad académica, como es la Hemeroteca Lingüística Virtual del proyecto Lengua y Prensa (www.lenguayprensa.uma.es). El análisis de algunos hitos cruciales servirá para reforzar una conclusión fundamental: pese al disfraz de inocencia con que suele arroparse (mediante su asociación a la gracia, al humor o a la simpatía como objeto de estudio antropológico), en otras ocasiones el discurso del odio al andaluz se despoja de todo ropaje para revelarse la más cruda intención de quien lo emite: la descalificación personal, el desprecio a una sociedad o la posición de superioridad.

\section{Palabras clave}

Lengua española; variedad andaluza; análisis del discurso; ideologías lingüísticas; discurso del odio. of the literary representation of Andalusian and of the linguistic ideologies reflected in the media. The latter are inventoried in a resource available to the entire academic community, such as the Virtual Linguistic Archive of the "Lengua y Prensa" project (www. lenguayprensa.uma.es). The analysis of some crucial landmarks will serve to reinforce a fundamental conclusion: despite the disguise of innocence with which it is usually dressed (through its association with grace, humour or sympathy as an object of anthropological study), on other occasions the hate speech to Andalusian reveals the crudest intention of the person who issues it: personal disqualification, contempt for a society or position of superiority.

\section{Keywords:}

Spanish language; Andalusian variety; discourse analysis; linguistic ideologies; hate speech.

\section{Advertencia teórica y metodológica}

De la actualidad del denominado discurso del odio ${ }^{1}$ da cuenta, por ejemplo, la elección de aporofobia 'rechazo al pobre' como palabra del año 2017 para la Fundación del Español Urgente (FundéuRAE); o, esta vez centrada en el tema que nos ocupa, la designación de la circunstancia como de andalufobia, que ha comenzado a circular por las redes sociales. Bajo el paraguas de dicha acción comunicativa se resguarda un continuum de prácticas discriminatorias en todos los ámbitos sociales que tiene como extremos desde las acciones más punibles (homofobia, xenofobia...) hasta las más tolerables, dentro de las cuales se encuentra el desprecio a todo lo andaluz mediante su asociación a determinados rasgos estereotipadores, observables desde la sociología (las condiciones económicas, el nivel cultural, los tipos pintorescos...); la psicología (la gracia, la actitud ante la vida, la simpatía...); y la dialectología (la forma de hablar). En cuanto a esta última, las muestras discursivas, numerosas, se propagan por la tradición literaria, los medios audiovisuales y de comunicación. En este trabajo se va a analizar un corpus representativo extraído, por una parte, de nuestra experiencia como investigadores de la variedad dialectal que es objeto de estudio y los rasgos sociológicos y psicológicos que habitualmente se le asocian; y, por otra, en el caso de los ejemplos relativos a los medios de comunicación, de la Hemeroteca Lingüística Virtual alojada en la página web del proyecto Lengua y Prensa. Las dos secciones del corpus corresponden a sendas calas en el análisis del discurso del odio al andaluz, representadas por dos vías: la filológica y la lingüística. A lo largo del trabajo, en el momento en que sea conveniente, se precisará este utillaje metodológico rudimentario.

1 Empleamos dicho sintagma siguiendo la definición del Consejo de Europa (2015: 3-4), donde se apunta que "el discurso de odio debe entenderse como fomento, promoción o instigación, en cualquiera de sus formas, del odio, la humillación o el menosprecio de una persona o grupo de personas, así como el acoso, descrédito, difusión de estereotipos negativos, estigmatización o amenaza con respecto a dicha persona o grupo de personas y la justificación de esas manifestaciones por razones de "raza", color, ascendencia, origen nacional o étnico, edad, discapacidad, lengua, religión o creencias, sexo, género, identidad de género, orientación sexual y otras características o condición personales” (la cursiva es nuestra). Consúltese también el trabajo de Díaz Soto (2015), quien revisa el concepto en el marco jurídico internacional. 


\section{Análisis}

\subsection{Saturación de la muestra}

Existe un principio fundamental de la estadística según el cual una muestra es representativa del todo que supone la realidad si los resultados a que llegamos tras su análisis no cambian, por muchos datos que sigamos añadiendo. Pues bien, algo semejante sucede con el análisis de la percepción de la variedad del español hablada en Andalucía. Puede aportarse una cantidad ingente de evidencia empírica -de la tradición libresca, del cine, de la televisión, de la prensa...-, pero lo que resulta incontestable es que la conclusión no varía. El andaluz sigue infravalorado, cuenta con poco prestigio en los ámbitos profesionales, se sigue caracterizando como habla de incultos y como mecanismo que mueve a la gracia, etc.

Los mismos investigadores parecen haberse dado cuenta de la saturación de los datos, como se puede comprobar por las citas de los textos de Antonio Narbona Jiménez: "Los estereotipos se repiten hasta el aburrimiento. Nada que no se sepa" $(A B C, 03.04 .2018) ;{ }^{2}$ o de Lola Pons Rodríguez, quien alude a la escasa efectividad de las argumentaciones esgrimidas por los especialistas: “[N]o tiene sentido sacar más argumentos lingüísticos o históricos” (El País, 02.02.2017). Por eso conviene traer a colación dicho principio estadístico: no merece la pena insistir más, no tiene sentido sacar los argumentos de siempre, ni tampoco aportar mayor evidencia, porque las conclusiones van a seguir siendo las mismas.

El esfuerzo de la crítica especializada, a fin de optimizar los resultados de la investigación, debería centrarse, más que en una ampliación de la muestra, ya de por sí saturada, en la búsqueda de nuevas perspectivas que sirvan no solo para corroborar las conclusiones, si es que hace falta corroborarlas aún más, sino también para ampliar el espectro de actuación. Decía Ramón y Cajal que "lo primero que se necesita para tratar de asuntos científicos, cuando no nos impulsa la misión de la enseñanza [y este no es ahora el caso], es tener alguna observación nueva o idea útil que comunicar a los demás" (1991 [1897]: [137]). La aportación de más muestras no viene más que a refrendar lo que ya se sabe, por lo que verdaderamente no existe avance en la investigación.

Así pues, si el estudio sobre la percepción social del andaluz progresa a modo de aluvión -es decir, cuantitativamente, ampliando cada vez más el corpus de trabajo, pero sirviendo solo para abundar en la caracterización ya conocida- entonces habrá que buscar nuevas vías de progreso, pero cualitativo, más que cuantitativo. Es entonces cuando surge la pregunta: ¿Cuáles podrían ser esas vías? En el estado actual de nuestras indagaciones hemos encontrado dos: una filológica y otra lingüística. Por ello, el análisis de la muestra se va a guiar por el desarrollo de la siguiente tabla, que funciona a modo de síntesis de nuestra exposición de los resultados, los cuales han sido obtenidos teniendo en cuenta las dos perspectivas apuntadas.

2 Sus palabras resuenan como el eco de una afirmación previa: “Cualquiera que se lo proponga puede reunir en poco tiempo una amplia antología de columnas y colaboraciones periodísticas, cartas al Director, etc., en las que se vierten los juicios más dispares sobre cómo hablan o deberían hacerlo o no hacerlo los andaluces" (2001: 12). 
Tabla 1. Nuevas vías de progreso cualitativo

\begin{tabular}{|l|c|c|c|}
\hline \multicolumn{2}{|c|}{ VÍA FILOLÓGICA } & \multicolumn{2}{c|}{ VÍA LINGÜÍSTICA } \\
\hline \multicolumn{2}{|c|}{ Rastreo histórico } & $\begin{array}{c}\text { Análisis Crítico del Discurso } \\
\text { política }\end{array}$ & $\begin{array}{c}\text { Columnismo } \\
\text { lingüístico }\end{array}$ \\
\hline fuentes librescas & $\begin{array}{c}\text { fuentes } \\
\text { periodísticas }\end{array}$ & $\begin{array}{c}\text { fuentes } \\
\text { audiovisuales }\end{array}$ & fuentes periodísticas \\
\hline \multicolumn{2}{|c|}{ DISCURSO DEL ODIO } \\
\hline
\end{tabular}

La vía filológica atiende al rastreo histórico de este discurso del odio, dirigiendo su mirada, por tanto, hacia las fuentes librescas, con la incorporación posterior, ya en el siglo XIX, de las periodísticas, y en el XX, de los modernos productos audiovisuales. Por su parte, la vía lingüística aborda la construcción de la realidad que estamos analizando desde la perspectiva del Análisis Crítico del Discurso, en tanto que este concibe cualquier práctica discursiva como de carácter social (Fairclough y Wodak, 1997) que siempre persigue objetivos ideológicos (van Dijk, 2015). Por nuestra experiencia, tomando esta vía, insistimos en cuestiones como la instrumentalización política o el columnismo lingüístico practicado por determinados autores en los medios de comunicación, a fin de mitigar la visión negativa de la variedad andaluza.

\subsection{La vía filológica}

El trabajo de Alberto González Troyano (2018: 9-37) aborda la imagen de lo andaluz desde finales del siglo XVIII hasta la actualidad. Tras el paso efímero de la Ilustración, gran parte de los estereotipos que perduran en el presente se crearon a partir de las descripciones de los viajeros románticos extranjeros. Y, pese a su noble empeño primigenio, no ayudó el costumbrismo a neutralizar las distorsiones perpetradas por aquellos. Más bien sirvió, sobre todo en el caso de los epígonos de Serafín Estébanez Calderón, para amplificarlas. Se insiste, pues, en el tópico sin que exista forma alguna de contener su ímpetu arrollador. El movimiento costumbrista evoluciona hasta convertirse en género perpetuado. A ello debe añadírsele la construcción, de forma interesada, por parte de la clase política de las regiones del centro y norte de la Península, de una serie de prejuicios en torno al andaluz, a fin de que como grupo dominante mantengan su posición.

Al hilo del diseño de esta jerarquía en las relaciones de poder, la sociolingüística crítica habla de la inferiorización del andaluz con respecto al territorio español restante (Rodríguez Iglesias, 2015: 99-104 y 2018: 98-109). La conversión del movimiento en género alcanza a los modernos productos audiovisuales, pues se identifica la existencia de ciertos personajes, por lo general de baja estofa y graciosos, con su procedencia andaluza, manifestada en su forma de hablar. Estamos hablando de decenas de series de televisión y de películas que han explotado el andaluz y su asociación con los ya conocidos estereotipos, sus actantes y sus escenarios. El estreno de Ocho apellidos vascos (2014) ha servido para reactivar la 
asociación. Los últimos hitos, a rebufo del éxito de la película, son la serie Allí abajo (2015) -donde el título evidencia la similitud entre la posición geográfica y jerárquica- y la película El mundo es suyo (2018). ${ }^{3}$

Mientras que las representaciones analizadas por González Troyano (2018) son más bien las literarias, sin adentrarse en la lengua, las de Rafael Cano Aguilar (2009: 82-111) apuntan a la valoración de la forma de hablar andaluza por parte de los eruditos. En líneas generales, la estrategia ideada por el investigador consiste en la búsqueda de dichas apreciaciones en los textos presentes en el Corpus diacrónico del español (CORDE) de la Real Academia Española, lo que le lleva a descubrir los primeros comentarios negativos al respecto en el siglo XVI, con algunos precedentes en el XV. Dentro de la filología, el ejemplo quizás más conocido sea el testimonio de Juan de Valdés, en referencia a Elio A. de Nebrija, en su Diálogo de la lengua (h. 1538). Las alusiones son tildadas por Cano Aguilar de "arbitrarias e infundadas" (2009: 87), al basarse en escasos datos a la par que erróneos, lo que probaría el escaso conocimiento de la variedad andaluza por parte del erudito conquense:

¿Vos no veis que, aunque Librija era muy docto en la lengua latina, que esto nadie se lo puede quitar, al fin no se puede negar que era andaluz, y no castellano, y que escribió aquel su Vocabulario con tan poco cuidado que parece haberlo escrito por burla? (Valdés 1984 [h. 1538]: 46).

[É]l era de Andaluzía, donde la lengua no stá muy pura (ibidem).

No me aleguéis otra vez para la lengua castellana el autoridad de Librija andaluz, que me haréis perder la paciencia (80).

Ya tornáis a vuestro Librija. ¿ iNo os tengo dicho que, como aquel hombre no era castellano, sino andaluz, hablaba y escribía como en Andalucía, y no como en Castilla? (114). ${ }^{4}$

En su rastreo, Cano Aguilar remonta el curso del tiempo hasta el siglo XX. Asimismo, Carriscondo Esquivel (1999) realizó el análisis de los textos pertenecientes a las colecciones costumbristas del XIX, muchos de ellos desconocidos por no estar en los grandes corpus de datos del español, salidos de la pluma de los epígonos de un movimiento que derivó en género, caracterizado por el olvido de sus propósitos primigenios (ya no se describe nada por temor a perderse ni se desea preservar lo auténticamente nacional). De este modo, se aporta a este recorrido histórico una serie de muestras representativas de la relación de la gracia andaluza con su forma de hablar; de los tipos pintorescos (toreros, cantaores y bandoleros) como actantes; de los escenarios (la corrala, la taberna) en que se mueven; y, finalmente, de las escenas repletas de chascarrillos, requiebros amorosos y piropeos:

3 Pueden señalarse otros productos audiovisuales, ordenados cronológicamente, como son Pixie y Dixie (1961), La vuelta al mundo de Willy Fog (1983), El color púrpura (1986), Los Fruittis (1989), Médico de familia (1995), Siete vidas (1999), Cuéntame (2001), Ana y los 7 (2002), Aquí no hay quien viva (2003), Acacias 38 (2015) y Anclados (2015). De todas estas muestras, queremos destacar aquí cómo, en el doblaje al español de El color púrpura (1986), el habla de los esclavos está impregnada de andalucismos para remarcar su bajo nivel socioeducativo. No hemos incluido en esta profusión de ejemplos el cine, producido durante el franquismo, de exaltación regional frente a propios y extraños, así como lo que parece ser su continuidad en los programas de la cadena autonómica Canal Sur. También hemos descartado a los presentadores de procedencia andaluza que son contratados precisamente por vincularse su forma de hablar a lo que podríamos denominar salero y desparpajo.

4 El análisis de estas observaciones a cargo de Ígor Rodríguez-Iglesias demuestra cómo es posible combinar la vía filológica (los orígenes de la ideología lingüística subyacente en esta visión del andaluz) con perspectivas críticas actuales, relacionadas con el ya comentado concepto de inferiorización (2018: 98-109) y el ahora introducido de decolonialismo (95-98). 
[El cantaor tiene que ser andaluz.] ¡Pero nunca de Jaén! Por lo tanto cecea y se sorbe una porción de letras, y hace muecas y gestos particulares al hablar, y al andar, y cuando está sentado, y yo creo que hasta mientras duerme (Ferrán 1872: 36).

[El matón nace] en Ronda o en Sevilla, ¿quién sabe?... pero si no es andaluz, lo parece. Flamenco por inclinación, dice jigo y jiguera, empleando constantemente la $z$ en lugar de la $c$ y la $s$, y adoptando un aire macareno... que da el opio (Ruigómez 1872: 229).

- ¿Es usted la madre de este pimpollo? -preguntó el nazareno. - Pa servir a usted y a Dios. -Pues debía usted parir todos los días. $-i P a$ darle a usted gusto, no es verdad? -No señora, para alumbrar la tierra. -¡Vaya que tiene el señor gana de bromas! Bien podría usted emplear el tiempo en otra cosa. -iEn qué mejor que en contemplar esa cara de azucena? (Díaz de Benjumea i1881?: 113).

El plan de actuación de los costumbristas poco a poco va cayendo en lo que antes acusaba, es decir, en el majismo, el tipismo y el pintoresquismo (vid. González Troyano, 2018: 39-46). Y todo ello para concluir que, en cuanto al español hablado en Andalucía se refiere, sus representaciones, presentes en estos textos, atañen solo a las clases populares (por el deseo de conferir a sus personajes gracia, chispa, salero...); no responden a un fiel deseo de reproducir dicha variedad lingüística, pues se trata ante todo de un estereotipo; y, por último, constituyen un recurso más del género costumbrista en aras de conferir a la trama una mayor comicidad. En definitiva, una tradición que ha trascendido fuera de la literatura y que ha cobrado realidad no por su existencia lingüística como variedad (pues no es hablada por nadie), sino por su recurrencia a la hora de imitar lo andaluz, similar a lo que sucedió en algunas producciones literarias de otras regiones, como el sayagués o el gauchesco de la literatura áurea y de la Región del Plata, respectivamente (vid. Coseriu 1981 [1973]: 312-313).

\subsection{La vía lingüística}

\subsubsection{Continuidad del discurso del odio}

Como una de las manifestaciones del discurso del odio al andaluz, el proceso de inferiorización contemplado en la vía filológica se transmite también por la lingüística. Las fuentes no son ahora los productos de entretenimiento -sean antiguos, sean contemporáneos- sino los medios de comunicación españoles, especialmente los contenidos de opinión. Tanto en la tradición decimonónica como en los modernos discursos audiovisuales el estereotipo sobre el andaluz se reviste de un halo de inocencia. Pese al disfraz (mediante su asociación a la gracia, a lo salao, al humor o a la simpatía como objeto de estudio antropológico), el valor es negativo porque sirve para insistir en el tópico, para acrecentarlo y, por tanto, mantenerlo. A la jerarquización que se ha tratado antes en series como Allí abajo (2015) (vid. 2.2.) se suma la ausencia de conflictos: el de arriba mira al de abajo (a su baja cultura y nivel social) con condescendencia, incluso con ternura, de un modo muy similar a como el occidental (perteneciente al mundo desarrollado) mira desde una perspectiva etnocéntrica al buen salvaje. Así, por ejemplo, puede verse la siguiente muestra, extraída de Barbijaputa en su blog Zona Crítica:

No sé cuántas veces he oído desde que vivo fuera de Andalucía frases como "tienes un acento bonito para ser andaluza", "no eres nada bruta para ser andaluza", "no eres la típica andaluza..." y en el aire queda flotando un "la típica andaluza... cateta". 
Sé que no hay ánimo de ofender y que, es más, me lo dicen como un halago, sin darse cuenta de que hay implícito un claro sentimiento de superioridad (Eldiario.es, 05.03.2015). ${ }^{5}$

Nos damos cuenta entonces de dos hechos fundamentales: la asociación de lo lingüístico con lo social y, además, la condescendencia como forma velada de desprecio y, por tanto, de odio implícito a lo andaluz, en el bajo estatus al que normalmente se le asocia y, por consiguiente, a su forma de hablar. No son sin embargo estas las únicas cuestiones detectadas en el discurso de los medios de comunicación. También se abordan otras, como la instrumentalización política de la variedad y su erección como vehículo de expresión informal. El arsenal de datos que sirve para comprobar estos hechos puede extraerse de un recurso como la Hemeroteca Lingüística Virtual del proyecto Lengua y Prensa, con numerosas muestras del nuevo cariz que está desarrollando este discurso del odio hacia el andaluz. No obstante, preferimos optar no por la cantidad sino por la calidad, a fin de evitar la saturación del material aportado (vid.2.1.). Es sobre todo el de la instrumentalización política, como arma de confrontación, el nuevo frente que se abre en torno al discurso del odio hacia el andaluz. Dicha instrumentalización se ve potenciada por la asociación del dialecto y sus hablantes a un nivel socioeducativo bajo.

\subsubsection{La instrumentalización política}

Ya hemos comentado que partimos de la consideración de que cualquier práctica discursiva es una práctica social con fines ideológicos determinados. En el asunto que tratamos, hemos detectado que hay numerosas ocasiones en que los discursos de desvalorización de la forma de hablar español en Andalucía se emplean con fines políticos. Y así, por ejemplo, en 2009, la diputada popular catalana Montserrat Nebrera calificó "de chiste" el acento de la ministra de Fomento, Magdalena Álvarez, que a la sazón es andaluza y socialista, a raíz de su gestión de la copiosa nevada que cayó en Madrid en enero de ese año y que colapsó la región. Y, tratando de justificar su calificativo, Nebrera echó más leña al fuego, al decir que el acento andaluz no se entiende ( $A B C, 11.01 .2009)$. Por su parte, en agosto de 2011, Juan Soler, portavoz adjunto del PP en la Asamblea madrileña, escribía en su blog que la forma de hablar de Trinidad Jiménez, ministra de Sanidad durante el gobierno socialista, "la hace más apta para Dos Hermanas [que es una localidad sevillana] o [para] Vélez-Málaga” y, por lo tanto, no está capacitada para liderar la lista del PSOE a la presidencia de la Comunidad de Madrid (ABC, 19.08.2011). Además, hay que dejar constancia del uso de la lengua para justificar argumentos nacionalistas de superioridad. En el caso que nos ocupa, Artur Mas, presidente de la Generalitat catalana, llegó a decir en septiembre de 2011 que "en Sevilla, Málaga o La Coruña hablan el castellano, [...] pero a veces no se les entiende. A veces no se les acaba de entender del todo" (El Mundo, 29.09.2011). Además, Ramón Silva, concejal socialista en el Ayuntamiento de Madrid afín a Pedro Sánchez, se mofó del acento de su correligionaria Susana Díaz durante las primarias del PSOE, a comienzos de marzo de 2017, cuando

5 En este ámbito, mediante las declaraciones vertidas en el artículo "La cuestión del acento neutro", Ígor Rodríguez-Iglesias advierte también lo que ha descrito académicamente: "Los actores de cine, teatro y doblaje. Los locutores de radio, los presentadores de televisión... todos estos profesionales dejan a un lado su manera de hablar que le es propia e imitan la inherente a los madrileños o burgaleses. Eso da cuenta de cómo, en el campo simbólico mediático, se manifiesta explícitamente esa ideología imperial de inferiorización de los otros a partir de un punto cero" (El País, 26.02.2016). Recientemente, en su programa de televisión, Pablo Motos preguntó a su colega Roberto Leal, que es andaluz, si iba a "suavizar" su acento cuando presentase el concurso Pasapalabra (Público, 05.05.2020). En estos últimos días estamos también asistiendo a un aluvión de opiniones, en los medios y en las redes sociales, acerca del acento andaluz de la ministra portavoz del gobierno, María J. Montero, todavía en fase de desarrollo, por lo que tendrá que ser objeto de análisis en un futuro próximo. 
dijo aquello de que querían "un PZOE ganadó" (La Vanguardia, 05.03.2017). Precisamente, el acento de Susana Díaz también fue objeto de burla y de una transcripción absurda por parte del cónsul español en Washington, en agosto de 2017, tomando como excusa la coincidencia en el color del vestido entre la presidenta andaluza y la reina de España cuando ambas coincidieron en un acto oficial (El Español, 01.08.2017). ${ }^{6}$

El análisis de las muestras sirve para reforzar una conclusión fundamental. Las disculpas llegan siempre tras el aluvión de críticas. Pero el daño ya está hecho. El discurso del odio al andaluz como variedad lingüística se despoja de todo ropaje para revelarse la más cruda intención de quien lo emite, que es la descalificación ya no social, sino personal (en las noticias que tienen a Magdalena Álvarez o Trinidad Jiménez como protagonistas); y el desprecio a una sociedad que vota a un determinado partido, el socialista, o a una determinada facción de ese partido, la susanista; sin olvidar, por supuesto, la traba lingüística que supone el acceso desde la periferia a la metrópoli. La descalificación y el desprecio como forma de odio. No resulta extraño, pues, que este discurso del odio al andaluz haya sido manejado en ámbitos como el político, para servir de herramienta con que enfrentarse al adversario y poner en duda su capacidad de liderar una determinada institución (sea un partido, un ministerio, una comunidad autónoma...); o emprender acciones gubernamentales. Con una simpatía que no deja de ser despectiva, el foráneo sonríe al andaluz por su forma de hablar y lo asocia a una forma de ser no precisamente prestigiosa desde el punto de vista de la tradición social. La política, conocedora de este componente del imaginario colectivo, lo explota a fin de extraer réditos. Y así, como arma de confrontación, el político no andaluz carga contra quien lo es para desprestigiar su forma de hablar y, a su vez, sus dotes políticas. Los partidos nacionales, que suelen tener entre sus filas a militantes de cualquier región española, deben hacer encajes de bolillos para, por una parte, exonerar al miembro que emite el exabrupto y, a su vez, recriminarle el desaire. Simultáneamente, las delegaciones territoriales de los partidos reaccionan de distinta forma en función de quien agrede.

Todos los ejemplos van en la misma línea. Sin olvidar tampoco que, aprovechando que el Pisuerga pasa por Valladolid, la defensa del andaluz se aprovecha para airear los trapos sucios del adversario y tratar así de sacarle los colores a la oposición en temas de desarrollo económico, derechos sociales, etc. Podemos ver esto ejemplificado precisamente en las noticias sobre la gestión de la nevada por parte de Magdalena Álvarez, donde figuran otros actantes que deciden intervenir en la polémica, como Gaspar Zarrías, destacado socialista andaluz, para acusar a la derecha en general del menosprecio a Andalucía; y en particular a Javier Arenas, por aquel entonces presidente de los populares andaluces, espetándole, Zarrías a Arenas, que carecía de autoridad en su partido $(A B C, 11.01 .2019)$; o Antonio Sanz, por aquel entonces secretario general del PP de la región, que a la vez que rechaza las declaraciones de su compañera de filas, Montserrat Nebrera, critica la gestión de la oposición, representada por Magdalena Álvarez, gestión que es la que realmente desprestigia a los andaluces -pero no porque sea andaluza, sino porque es socialista-, así como critica su carácter chulesco y soberbio, para finalmente arremeter contra Gaspar Zarrías, acusándolo de lanzar una cortina de humo para ocultar los datos del paro en Andalucía (ibidem). Como puede comprobarse, estos temas guardan una relación nula con la forma de hablar,

6 A raíz de este suceso Lola Pons Rodríguez escribió su columna “El cónsul y los vendimiadores”. En dicho texto la autora pone claramente el dedo en la llaga, al situar el problema lingüístico en el ámbito de lo socioeconómico: "No es de la lengua de lo que estamos hablando. De nuevo hay que citar la divisa de la campaña de Clinton: es la economía, estúpido. Y ni siquiera es solo la economía. Se está hablando de supremacías que se quieren defender" (El País, 02.08.2017). 
si no fuera por la ejecución de un plan orquestado para relacionarlos desde la política. Lo mismo que sucede con otros aspectos, como los económicos (lo hemos visto en la columna de Lola Pons Rodríguez, vid. n. 6) o los educativos, de los que lamentablemente contamos también con numerosas muestras representativas. ${ }^{7}$

\subsubsection{Del lego al especialista}

Las experiencias conocidas por los medios funcionan, según la terminología de Patrick Charaudeau (2003 [1997]: 187223) a modo de "acontecimientos referidos", que pueden ser comentados ("acontecimientos comentados") y confrontados ("acontecimientos provocados"). Mientras que en el comentario, facilitado gracias a las nuevas tecnologías presentes en los medios, se mezclan profanos y conocedores de los acontecimientos referidos, en la confrontación, sin embargo, se apela al saber de estos últimos. Así pues, el nivel de especialización en la reacción a los acontecimientos es un continuum que va de menos, en el caso de las opiniones de los lectores, a más, en el caso de los divulgadores y el cultivo de un subgénero periodístico como es el de la columna de opinión.

\subsubsection{La irrupción de los lectores}

La sección de comentarios a las noticias publicadas en los diarios digitales son una muestra evidente de la democratización de la opinión pública. Los comentarios de los lectores que habitan los ecosistemas digitales no tienen desperdicio desde el punto de vista discursivo, en tanto que son componentes recién llegados a estos ecosistemas, y ocupan escenarios que hasta este momento solo tenían manifestación visible en la sección de Cartas al Director, donde se producía una criba más estricta de la participación de los lectores. No obstante, estos textos constituyen un objeto de estudio bastante complicado de analizar porque los investigadores carecemos de datos, no aportados por los participantes, que sin duda arrojarían información de especial relevancia. De todas formas, este inconveniente no resta valor a los discursos que la ciudadanía ofrece. Nos referimos, por ejemplo, a los cuestionarios lingüísticos, cuyo empleo no siempre gozan de la espontaneidad y la ausencia de presión brindada por los medios digitales (anonimato, inducciones en las respuestas, etc.).

De un pequeño corpus de comentarios que será analizado con más profundidad en otro trabajo, ${ }^{8}$ hemos seleccionado un grupo de comentarios que nos permite aportar someramente unas conclusiones relacionadas con ideologías lingüísticas sobre el andaluz, resultado de un largo y arbitrario proceso de desprestigio y desvalorización no solo como variedad dialectal, también de sus hablantes. En los comentarios analizados observamos tres circunstancias que queremos subrayar:

7 Aquí pueden clasificarse noticias sobre determinadas preguntas, tales como las publicadas en una entrevista a la cantante andaluza Melody en un programa de televisión: “¿Cómo es que siendo de Dos Hermanas hablas tan fina? ¿Has estudiado?” (ABC, 27.08.2014); o las que aluden al nivel de alfabetización de Andalucía: "Ana Mato llama analfabetos a los niños andaluces" (El País, 01.03.2008); “Tejerina: En Andalucía lo que sabe un niño de 10 años es lo que sabe uno de ocho en Castilla y León” (El País, 18.04.2018). Estas declaraciones se repiten cíclicamente, en plena campaña de las sucesivas elecciones al Parlamento andaluz, por parte de miembros del Partido Popular. Consecuentemente, se erigen en un arma de confrontación política, a fin de desgastar el trabajo realizado por el PSOE, que ha sido el gobernante en la comunidad autónoma desde sus inicios hasta fechas recientes. En contraste puede observarse también, aunque con una frecuencia muchísimo menor, un uso del andaluz, llamémosle endógeno, a fin de generar empatías o sinergias entre los candidatos y el electorado. Vid. al respecto la columna de Lola Pons Rodríguez titulada “Con acento andaluz" (El País, 30.11.2018). Este uso endógeno también puede advertirse en otros ámbitos, como el publicitario, tal como ha demostrado en sus estudios Elena Leal Abad (2019).

8 Hemos recopilado un corpus que contiene dos mil comentarios vertidos en un total de diez noticias en la prensa digital donde el andaluz figura ya sea como protagonista, ya como personaje secundario, pero que dan pie a que la mayoría de opiniones gire en torno a ideologías lingüísticas relacionadas con la desvalorización del andaluz (y, en ocasiones, de otras variedades del español). Los comentarios que aquí manejamos no han sufrido ninguna adaptación ortográfica. 
por un lado, la confusión terminológica presente en la ciudadanía en torno a la definición del andaluz; por otro, el desprecio absoluto de la variedad y la discriminación a sus hablantes; $y$, finalmente, el menosprecio de quienes hablan otras variantes del español de España diferentes a la castellana por su idiosincrasia lingüística.

No existe consenso sobre cómo debe caracterizarse el andaluz (lengua, dialecto, habla, modalidad o variedad lingüística). Ni tan siquiera hay acuerdo en reconocerlo como una unidad, más allá de los estudios lingüísticos que dividen Andalucía en una región oriental y otra occidental. La variedad terminológica, que Elena Méndez García de Paredes define como "lastre teórico y conceptual" (2003: 216), es transmitida a la población por medio de la educación y por ende los libros de texto escolares, que emplean una terminología que no contribuye a erradicar las desigualdades y discriminaciones por razón de lengua. En los comentarios recopilados hemos podido evidenciar dicha indeterminación. A la pregunta de qué es el andaluz, la mayoría comenta que es un "acento"; y, en menor medida, "dialecto"; y, aún menos, "habla".

Los conceptos de lengua, dialecto y habla ocultan un trasfondo ideológico empleado habitualmente con fines discriminatorios. A esta discriminación contribuye ese constructo idealista y ficticio que es el de la lengua estándar, al que el andaluz y el resto de variedades quedan supeditados. El hecho de que la variedad castellana sea la que históricamente se ha difundido de forma mayoritaria e impuesto por distintas razones ideológicas ha dado lugar a que gran parte de los españoles, entre ellos los andaluces, escuchen con desagrado otras variedades de la misma lengua, al igual que ciudadanos profanos en asuntos lingüísticos traten de erigirse, con sus opiniones, en expertos que juzgan a quienes se alejan del estándar, próximo a, pero no identificado con, la variedad castellana. De ahí que existan opiniones peyorativas como las siguientes:

Ahora resulta que el Andaluz es un dialecto... en vez de un castellano mal hablado (El Mundo, 01.08.2017).

El andaluz es una deformacion del castellano. No es un dialecto (El Español, 01.08.2017).

Ni el andaluz ni el canario son el idioma español, sino aberraciones del mismo (Voz Libre, 28.08.2014).

[N]o hay forma de entender a un andaluz hablando (El Mundo, 01.08.2017).

Del mismo modo -sin ánimo de insultar, pero con una evidente superioridad- hay otros usuarios que definen el "acento andaluz" como "gracioso", "peculiar" o "curioso". Es primordial dejar patente que las burlas no van dirigidas al andaluz como variedad lingüística sino a las personas, de manera que son sus hablantes los despreciados e infravalorados. El problema es poliédrico y, por lo tanto, su análisis es abordado por lingüistas, pero también por sociólogos, antropólogos, filósofos...; en definitiva, todos aquellos cultivadores de las ciencias humanas que persiguen como objeto de estudio las interacciones sociales en relación con determinadas variables. Sin duda, tras el desprestigio del andaluz no existen razones lingüísticas, sino más bien sociopolíticas, pues debemos tener presente que "language ideologies represent the perception of language and discourse that is constructed in the interest of a specific social or cultural group" (Kroskrity, 2004: 501).

Estas ideologías, una vez creadas, se perpetúan, se extienden y son muy difíciles de erradicar, aún más cuando el grupo que sufre la opresión colabora como parte implicada. De hecho, sobre esta realidad también hemos encontrado numerosos testimonios de personas que se definen como andaluzas y se avergüenzan de la forma como se habla en Andalucía. Parecen ser estas víctimas cómplices, colaboradores necesarios en la perpetuación de la idea de que se habla mal en la región. Por todo ello, coincidimos con Pierre Bourdieu (2008: 29) cuando afirma que “[c]ualquier dominación simbólica 
implica, por parte de los que la sufren, una cierta complicidad". Advertía Martín Rojo (1997: 24) que los prejuicios lingüísticos conducen a una deslegitimación de los discursos basada en excluir "lo que se dice y a quien lo dice, sobre la base de cómo lo dices". Y es así como detectamos, en hablantes andaluces, comentarios que comulgan con el tópico de que en Andalucía se habla un mal español:

[L]os andaluces tenemos acentos graciosos (Libertad Digital, 29.11.2011).

[L]os andaluces hablamos mal pero tampoco hay que vanagloriarse de ello (El Mundo, 01.08.2017).

El andaluz es un dialecto, un dialecto oral (escribir escribimos como el resto de hispanohablantes). Por supuesto que al ser un dialecto se puede transcribir, pero se transcribe al castellano (El Mundo, 01.08.2017).

Finalmente, hemos advertido la presencia de comentarios que, además de recriminar el andaluz, desprecian a los hablantes de otras variedades que también sufren acoso, en este caso por ser de comunidades autónomas donde se habla una segunda lengua oficial (gallego, euskera y catalán). Los especialistas han señalado la asimetría existente en España en cuanto al tratamiento sociopolítico de las lenguas cooficiales. En las comunidades monolingües parece no haber un aprecio por las lenguas de España y, como ha comentado Ángel López García-Molins (2012:173), las lenguas autonómicas son allí consideradas extranjeras. Y en este grupo se incluyen los andaluces. Esto es una muestra de cómo las víctimas muchas veces se convierten en verdugos y buscan nuevos sujetos para seguir llevando a cabo la opresión (Tusón 1996: 56). De este modo, podemos leer opiniones como las siguientes:

[Q]ue me diga como tiene que hablar un andaluz, nos lo diga un catalán... jajajajaja. Si no se les entienden, siempre con la papa en la boca (El Mundo, 01.08.2017).

A mí también me hacen gracia (sana) oir a un vasco, catalán, madrileño, gallego o murciano (Libertad Digital, 29.11.2011).

[E]l gallego [...] suena como castellano 'mal hablado' (El País, 01.08.2017).

En España nos hemos descojonado de los gallegos, de los vascos, de los catalanes, de los de Madrid, de los extremeños por sus acentos (El País, 01.08.2017).

En Andalucia se habla andalù... ya puedes empezar por decirle a los gallegos, asturianos, catalanes etc., etc. que hable castellano (El País, 01.08.2017).

\subsubsection{La opinión autorizada de los especialistas}

Solo de una intuición lingüística pueden emanar determinadas creencias, positivas o negativas, sobre una lengua o una de sus variedades. En un trabajo reciente, Carriscondo Esquivel (2019: 210-213) ha expuesto los contraargumentos con los que los columnistas tratan de minimizar los efectos de aquellas creencias y actitudes que, en lo referente al andaluz, constituyen un imaginario lingüístico negativo (vid. Houdebine, 2002). Para ello se basó en los trabajos de Luis Cortés Rodríguez, catedrático emérito de Lengua Española de la Universidad de Almería, ya que (1) posee un amplio repertorio de publicaciones académicas especializadas sobre los temas que trata de divulgar en sus textos periodísticos; (2) en dicha producción se comprueban los rasgos definitorios del subgénero periodístico denominado columnas sobre la lengua (vid. Marimón Llorca, 2016: 72-74, 2018: 174-176); y (3) posee un corpus consolidado de muestras textuales, de tal manera que, 
tras la publicación de sus columnas en un medio regional ( $L a$ Voz de Almería), decide reunirlas todas bajo un mismo título (vid. Cortés Rodríguez, 2011, 2013 y 2019).

Los contraargumentos con los que trata de minimizar el imaginario lingüístico negativo que se cierne en torno al andaluz -procurando reproducirlos literalmente y estableciendo un orden jerárquico, de lo general a lo particular- son los siguientes: (1) no hay acentos mejores ni peores (03.02.2009); (2) hablar bien no depende de la variedad (01.02.2010, 29.11.2010); (3) hablar bien depende de la riqueza y la adecuación léxica, de la forma de conectar los actos discursivos, de la manera de manejar las pausas, etc. (01.02.2010); (4) el andaluz no es un atentado contra el español correcto (01.02.2010); (5) en Andalucía no existe un habla única (01.02.2010); (6) como en cualquier otra variedad, existe un buen y un mal andaluz (01.02.2010); y (7) existe una clara vocación internacional de las hablas meridionales (15.08.1993 y 01.02.2010). Contraargumentos como el tercero formarían parte de los denominados comunicativos, si bien algunos de ellos se aproximan a apreciaciones impresionistas; por ejemplo, al calificar la morfosintaxis meridional de más pura, reglamentada y correcta (13.12.2010) o que el andaluz, "cuando es un buen andaluz, suena maravillosamente" (01.02.2010). ${ }^{9}$

\section{Conclusiones}

En estas dos calas (desde la tradición libresca hasta la prensa digital) y en nuestra clasificación del discurso del odio al andaluz en todas las manifestaciones detectadas y sus usos instrumentales (desde la inocencia disfrazada hasta la descalificación del adversario político), creemos haber aportado algo más que una simple acumulación de datos, dentro de los síntomas de saturación que ya comienza a percibirse, tanto en los temas como en las muestras que sirven de evidencia empírica. Permítasenos manifestar ahora, al final del trabajo, nuestro pesimismo a la hora de superar esta archiconocida estereotipación, rayana en el estigma. Si los expertos no han podido ni siquiera mitigarla en su labor periodística divulgativa, mucho menos, pensamos, vamos a poder hacer nosotros por medio del discurso especializado en un contexto académico. Los comentarios de los lectores de los medios de comunicación digitales atestiguan la vigencia del discurso del odio al andaluz. Acabamos igual que al inicio, con la mención a otro principio fundamental de la estadística: si la muestra es representativa, se puede predecir el comportamiento de los datos que surjan en el futuro. Pese a todo lo comentado, no nos cansaremos de apelar a la justificación social de la investigación realizada por aquellos que se acerquen a estos asuntos, con el deseo de que la divulgación, la sensibilización o la explicación científica de la realidad sirvan algún día para contrarrestar los efectos negativos, arañándole poco a poco terreno a los dominios del tópico.

9 El uso de estos argumentos trascendería el propósito de prestigiar el dialecto y convencer a los hablantes del idéntico estatus en que se sitúa la variedad vernácula frente a otras más prestigiosas (vid. Marimón Llorca, in press: 18). La cuestión de los acentos remite directamente al nivel fónico. Y, al respecto, no se impone una pronunciación ejemplar, pero goza de mayor prestigio, como se sabe, la castellana. 


\section{Referencias bibliográficas}

Bourdieu, P. (2008). ¿Qué significa hablar? Economía de los intercambios lingüísticos. Madrid: Akal.

Cano Aguilar, R. (2009). “Lengua e identidad en Andalucía: visión desde la historia”, en Narbona Jiménez, A. (coord.). La identidad lingüística de Andalucía, 67-131. Sevilla: Centro de Estudios Andaluces.

Carriscondo Esquivel, F. M. (1999). Literatura y dialectología. Córdoba: Obra Social y Cultural de CajaSur.

Carriscondo Esquivel, F. M. (2019). "La periferia meridional frente al centro en el columnismo sobre la lengua", en

Marimón Llorca, C. (ed.). El columnismo lingüístico en España desde 1940. análisis multidimensional y caracterización genérica, 209-229. Madrid: Arco Libros.

Charaudeau, P. (2003). El discurso de la información. La construcción del espejo social [1997]. Barcelona: Gedisa.

Consejo de Europa (2015). Recomendación General no 15 sobre Líneas de Actuación para combatir el discurso de odio. (Trad. Al español: Ministerio de Asuntos Exteriores, Gobierno de España). Disponible en: https://rm.coe.int/ ecri-general-policy-recommendation-n-15-on-combating-hate-speech-adopt/16808b7904

Cortés Rodríguez, L. (2011). El español que hablamos. Malos usos y buenas soluciones. Almería: Universidad de Almería.

Cortés Rodríguez, L. (2013). El español que hablamos. Malos usos y buenas soluciones, $2^{\text {a }}$ ed., muy aumentada. Almería: Universidad de Almería.

Cortés Rodríguez, L. (2019). El habla nuestra de cada día. 102 reflexiones sobre buenos y malos usos en nuestro idioma. Almería: Universidad de Almería.

Coseriu, E. (1981). "La lengua funcional” [1973], en Lecciones de lingüística general, versión española de José M. Azáceta y García de Albéniz revisada y, en parte, reelaborada por el autor. [287]-315. Madrid: Gredos.

Díaz de Benjumea, N. (i1881?). “La Semana Santa en Sevilla. Cuadro Primero”, en Varios Autores. Los hombres españoles, americanos y lusitanos pintados por sí mismos. Colección de tipos y cuadros de costumbres peculiares de España, Portugal y América, escritos por los más reputados literatos de estos países, bajo la dirección de don Nicolás Díaz de Benjumea y don Luis Ricardo Fors, e ilustrada con multitud de magníficas láminas debidas al lápiz del reputado dibujante don Eusebio Planas, 104-113. Barcelona: Establecimiento Tipográfico Editorial de Juan Pons.

Díaz Soto, J. M. (2015). “Una aproximación al concepto de discurso del odio”. Revista Derecho Estado, 34, 77-101. DOI: http://dx.doi.org/10.18601/01229893.n34.05

Fairclough, N. \& Wodak, R. (1997). “Critical discourse analysis”, en T. van Dijk (ed.). Discourse Studies: A Multidisciplinary Introduction. vol. 2, 258-284. London: Sage.

Ferrán, A. (1872). "El cantador", en Varios Autores. Los españoles de ogaño. Colección de tipos de costumbres dibujados a pluma, vol. 2, 32-42. Madrid: Librería de Victoriano Suárez, 2 vols.

González Troyano, A. (2018). La cara oscura de la imagen de Andalucía. Estereotipos y prejuicios. Sevilla: Centro de Estudios Andaluces.

Houdebine, Anne-M. (2002). L'imaginaire linguistique. Paris: L’Harmattan. 
Kroskrity, P. V. (2004). “Language Ideologies: Emergence, Elaboration, and Application”, en Duranti, A. (ed.). A Companion to Linguistic Anthropology, 496-517. Oxford: Blackwell.

Leal Abad, E. (2019). "El andaluz en la publicidad: Niveles de lengua y contenido del mensaje”, ponencia presentada en las V Jornadas del Español en Canarias (Universidad de La Laguna, 25.04.2019).

Lengua y Prensa (en línea). Hemeroteca lingüistica virtual, <http://www.lenguayprensa.uma.es>.

López-García Molins, Á. (2012). “La política lingüística del Estado”, en Monteagudo, H. (ed.). Linguas, sociedade e política. Un debate multidisciplinar, 169-196. Santiago: Consello da Cultura Galega.

Marimón Llorca, C. (2016). "Rhetorical Strategies in Speech about Language: the Persuasive Resource of Ethos". Res Rethorica, 1, 67-89. DOI: https://doi.org/10.17380/rr2016.1.5

Marimón Llorca, C. (2018). “La Academia Española trabaja”. Actitudes lingüísticas y estrategias valorativas en las columnas sobre la lengua (CSL)”. Cuadernos AISPI, 12, 169-190. DOI: https://doi.org/10.14672/0.2018.1494

Marimón Llorca, C. ([in press]). "La lengua y las lenguas: imaginarios lingüísticos sobre la diversidad en la prensa española contemporánea”. Lingüística Española Actual, [1-21].

Martín Rojo, L. (1997). “El orden social del discurso”. Discurso, 1, 1-37.

Méndez García de Paredes, E. (2003). "El habla andaluza en los libros de texto escolares". Cauce: Revista Internacional de Filología, Comunicación y sus Didácticas, 26, 207-230. Disponible en: http://institucional.us.es/revistas/cauce/26/ mendez.pdf

Narbona Jiménez, A. (2001). “Prólogo”, en Actas de las Jornadas sobre el Habla Andaluza. Historias, Normas, Usos, 11-16. Estepa (Sevilla): Ayuntamiento de Estepa.

Ramón y Cajal, S. (1991). Reglas y consejos para la investigación científica. Los tónicos de la voluntad [1897]. Madrid: Espasa-CALPE.

Real Academia Española (en línea). Corpus Diacrónico del Español (CORDE), <http:// http://corpus.rae.es/cordenet. html>.

Rodríguez-Iglesias, Í. (2015). "La hybris del punto cero metalingüístico sobre el valor indexical: la lengua como marcador de la heterojerarquía de dominación”. Otros Logos. Revista de Estudios Críticos, 6, 91-115. Disponible en: http://www. nuevarevistadelpacifico.cl/index.php/NRP/article/view/71

Rodríguez-Iglesias, Í. (2018). "La ideología lingüística de Juan Valdés sobre el andaluz desde una perspectiva decolonial. Hito en la construcción del privilegio lingüístico". Circula. Revue d'Idéologies Linguistiques, 7, 91-114. DOI: https://doi. org/10.17118/11143/14498

Ruigómez, A. (1872). "El matón", en Varios Autores (1872). Los españoles de ogaño. Colección de tipos de costumbres dibujados a pluma, vol. 2, 224-236. Madrid: Librería de Victoriano Suárez, 2 vols.

Tusón, J. (1996). Los prejuicios lingüísticos. Barcelona: Octaedro.

Valdés, Juan de (1984). Diálogo de la lengua [h. 1538], ed. de Juan M. Lope Blanch. Madrid: Castalia. van Dijk, Teun A. (2015). “Cincuenta años de estudios del discurso”. Discurso y Sociedad, 9, 1-2, 15-32. 